\title{
EVALUATION OF PERCEIVED STRESS LEVELS AND ITS SOURCE AMONG DENTAL STUDENTS: A CROSS-SECTIONAL STUDY
}

\author{
Praveen K Kodumuri ${ }^{1}$, Christofer Thomas ${ }^{2}$, Purna Singh $A^{3}$, Shivanand Rathod ${ }^{4}$ \\ ${ }^{1}$ Assistant Professor, Department of Physiology, Mamata Medical College, Khammam, Telangana. \\ ${ }^{2}$ Assistant Professor, Department of Physiology, Sapthagiri Institute of Medical Sciences and Research Centre, Bangalore. \\ ${ }^{3}$ Assistant Professor, Department of Physiology, College of Medicine, King Faisal University, Kingdom of Saudi Arabia. \\ ${ }_{4}^{4}$ Associate Professor, Department of Physiology, Mamata Medical College, Khammam, Telangana.
}

\begin{tabular}{l}
\hline ABSTRACT \\
CONTEXT \\
Recent reports show high amount of academic stress among the students and chronic stress is shown to have a negative effect \\
on cognitive functioning and learning of students.
\end{tabular}

\section{AIMS}

The purpose of study was to determine the prevalence of self-perceived stress among dental students and to observe any possible association between the levels of stress and (a) academic year, (b) motivation to study dental science, (c) medium of study at 10+2 level, (d) mother tongue, (e) presence of perceived physical problems.

\section{SETTINGS AND DESIGN}

The entire dental students in the five academic years of the Mamata Dental College were selected for the study. The study was cross-sectional in design.

\section{METHODS AND MATERIAL}

We used the Kessler 10 Psychological Distress instrument (K10) to assess the psychological stress along with a semi-structured questionnaire for the socio-demographic details.

\section{STATISTICAL ANALYSIS USED}

Descriptive statistics were used for summarizing the study and outcome variables. Pearson's chi-square test was used to see for the association between a categorical outcome and different study variables. P value of $<0.05$ was considered significant.

\section{RESULTS}

Results show the association between the psychological stress and the category of admission to the course. We also found an association between the students who perceived physical problems as a source of stress and the level of stress.

\section{CONCLUSIONS}

Our study shows significant association between two study variables and the psychological stress score. First one is the perception of physical problem as source of stress and the second outcome variable was the category of admission to the dental course.

\section{KEYWORDS}

Perceived Stress, Dental Students, Cognitive Function.

HOW TO CITE THIS ARTICLE: Kodumuri PK, Thomas C, Singh PA, et al. Evaluation of perceived stress levels and its source among dental students: a cross-sectional study. J. Evolution Med. Dent. Sci. 2016;5(52):3425-3428, DOI: 10.14260/jemds/2016/791

\section{INTRODUCTION}

Stress is defined as "the real or interpreted threat to the physiological or psychological integrity of an individual that results in altered physiological and behavioural responses. ${ }^{1} \mathrm{~A}$ stressor can be defined as a "change in the environment that is sensed by human, which is aversive and potentially harmful to that him/her and elicits acute and/or chronic responses." 2 Stressors can be by thoughts, beliefs and attitudes or can be

Financial or Other, Competing Interest: None.

Submission 04-05-2016, Peer Review 04-06-2016,

Acceptance 09-06-2016, Published 30-06-2016.

Corresponding Author:

Dr. Praveen K Kodumuri,

Department of Physiology,

Mamata Medical College,

Khammam, Telangana.

E-mail: pkphysio@gmail.com

DOI: $10.14260 /$ jemds $/ 2016 / 791$ due to loss or tragedy. Acute stress is usually beneficial, whereas chronic stress is known to be deleterious. Chronic exposure to stressful conditions lead to shift in the homeostatic machinery, which in turn brings about altered homeostasis. Further, prolonged exposure to chronic stress increases the allostatic load and triggers the release of cortisol and cytokines and other inflammatory molecules, which seriously perturbs physiological and psychological homeostasis leading to tissue damage and cognitive deficits.

Recently, stress during academic training is increasingly being reported. The academic stress has been leading to poor performance among the students among various disciplines. 3,4 This perceived stress could be of various factors like socioeconomic, anxiety of a steady career or getting a job. Among the various disciplines, medical and dental disciplines have been reported the greatest perceived stress among the students. The reason could be due to the number of subjects 
they learn, the depth in which they have to learn and so on. Previous studies have shown fairly high levels of distress, such as symptoms of depression anxiety and even suicide thoughts among medical undergraduates.5,6,7

Like Medical education, Dental education is also being considered as one of the most challenging and stressful field of study. Stress among these students also could be multifactorial, arising from both the academic, social and support issues. Studies on the perceived stress and the causative factors in medical students have been greatly looked into, but the data among the dental students are scare. In Telangana, local epidemiological data about perceived stress and possible factors associated with perceived stress among dental undergraduate students is less. Thus the present study was therefore carried out to determine the prevalence of selfperceived stress among dental students in Mamata Medical College, Telangana and to observe any possible association between the levels of stress with (a) academic year, (b) mode of admission into the course, (c) motivation to join the course, (d) mother tongue (f) language medium at school level and (g) presence of perceived physical problems.

\section{SUBJECTS AND METHODS Instrument}

We used the Kessler 10 Psychological Distress instrument (K10).[8] The K10 questionnaire was observed to have good psychometric properties with a Cronbach's alpha of 0.89 [95\% Confidence Interval (CI) [0.88-0.90]. This instrument is used to measure the previous one month's distress. The scoring of the scale is as follows; a score of less than 20 is considered as nil stress, while a score of 20-24 is mild stress, 25-29 is moderate stress and $30-50$ is severe stress.

\section{Study Subjects}

All the male and female dental students in the four academic years and the students doing internship of the Mamata Dental College, Khammam, were invited to complete the bilingual (Telugu and English) version of the K10 self-administered, anonymous questionnaire during the 2013-2014 academic year.

\section{Ethical Clearance}

All students who participated in the study were informed about the objectives of the study, and the information about the instrument was explained. Approval for conducting the study was obtained from the Research Ethical Committee of the Mamata Dental College, Khammam.

\section{Collection of Data}

Completed questionnaires were collected before the subjects either one month before the exam or one month after the exam period, so that the examination stress would not affect the responses of the students. It was practically difficult to find a single day to administer the questionnaire, as there were internal assessment tests falling for some batch of students. Responses to additional questions relating to sources of stress, medical illness in the past four weeks and how many days a student was not able to work were also collected. The participation was entirely voluntary.

\section{Analysis of Data}

Data were entered in Microsoft Excel and analysed using GRAPHPAD PRISM software. All the responses were entered and three levels of stress (Mild, moderate and severe) were calculated and put as one category. Descriptive statistics (Mean, standard deviation and percentages) were used for summarizing the study and outcome variables. Pearson's chisquare test was done to look into the association between the stress group and different study variables. Student's t-test for independent samples was used for comparing the mean values of continuous study variables in relation to stress levels. $\mathrm{P}$ value of $<0.05$ was considered significant.

\section{RESULTS}

A total of 290 students were given the questionnaire and the completed questionnaires were received from 273 students (Response rate of $74.0 \%$ ). The respondent's demographic details are shown in Table 1; $24 \%$ of our respondents were males and $75 \%$ were females. The college has more female students compared to male students, which are the reason behind such big ratio difference. The mean age of the respondent was 19 years (SD 0.5). There were more of (23\%) first year students and the least were from the final year students (15\%). There was no much difference in the category of admission either it be government quota or in management quota; $47 \%$ of the students joined the course with no special interest for the BDS course. Telugu was the mother tongue of most of the students (78\%) and English being the medium at their school level (90\%), Table 1.

\begin{tabular}{|c|c|}
\hline Parameters & Frequency (Percentage) \\
\hline \multicolumn{2}{|c|}{ Gender } \\
\hline Male & $66(24.2 \%)$ \\
\hline Female & $207(75.8 \%)$ \\
\hline \multicolumn{2}{|c|}{ Academic Year } \\
\hline Ist year & $69(23.5 \%)$ \\
\hline IInd Year & $50(18.3 \%)$ \\
\hline IIIrd Year & $50(18.3 \%)$ \\
\hline IVth Year & $62(22.7 \%)$ \\
\hline \multicolumn{2}{|c|}{ Category of Admission } \\
\hline Government quota & $147(53.8 \%)$ \\
\hline Management Quota & $126(46.2 \%)$ \\
\hline \multicolumn{2}{|c|}{ Motivation for the Study } \\
\hline Self interest & $81(29.7 \%)$ \\
\hline Family choice & $62(22.7 \%)$ \\
\hline No motivation & $130(47.6 \%)$ \\
\hline \multicolumn{2}{|c|}{ Mother Tongue } \\
\hline Telugu & $246(90.1 \%)$ \\
\hline Hindi & $7(2.6 \%)$ \\
\hline Urdu & $15(5.5 \%)$ \\
\hline English & $5(1.5 \%)$ \\
\hline \multicolumn{2}{|c|}{$\begin{array}{l}\text { Medium (Language) of } \\
\text { Instruction at School }\end{array}$} \\
\hline Telugu & $55(20.1 \%)$ \\
\hline Urdu & $3(1.1 \%)$ \\
\hline English & $215(78.8 \%)$ \\
\hline Table 1: Socio-Der & c Distribution-Freq \\
\hline
\end{tabular}


The mean K10 score of the participants was 21.08 (SD 6.43) out of a maximum score of 50 . The score varied from 10 to $50 ; 58 \%$ of the respondents had stress, either mild or moderate or severe, Table 2 . Among the stress group category $27 \%$ suffered from mild stress, $17 \%$ moderate stress and $12 \%$ severe stress Table 2.

\begin{tabular}{|c|c|}
\hline Presence of Stress & Frequency (Percentage) \\
\hline Absent & $114(41.8 \%)$ \\
\hline Present & $159(58.2 \%)$ \\
\hline \multicolumn{2}{|c|}{ Table 2: Presence or Absence of Stress among } \\
Students of all the Academic Years
\end{tabular}

Year wise segregation of stress severity revealed that first year students suffered from stress in the entire three categories; mild, moderate or severe; $42 \%$ of the students had no stress and among them fourth year students (30\%) had least stress Table 3 .

\begin{tabular}{|c|c|}
\hline Stress Category & Frequency (Percentage) \\
\hline No Stress & $115(42.1 \%)$ \\
\hline Ist year & $24(20.8 \%)$ \\
\hline IInd Year & $22(19.1 \%)$ \\
\hline IIIrd Year & $17(14.78 \%)$ \\
\hline IVth Year & $30(26 \%)$ \\
\hline$V^{\text {th }}$ Year & $22(19.1 \%)$ \\
\hline Mild Stress & $76(27.8 \%)$ \\
\hline Ist year & $25(32.8 \%)$ \\
\hline IInd Year & $11(14.47 \%)$ \\
\hline IIIrd Year & $13(17.1 \%)$ \\
\hline IVth Year & $17(22.36 \%)$ \\
\hline$V^{\text {th }}$ Year & $10(13.15 \%)$ \\
\hline Moderate Stress & $49(17.9 \%)$ \\
\hline Ist year & $11(22.44 \%)$ \\
\hline IInd Year & $10(20.4 \%)$ \\
\hline IIIrd Year & $9(18.36 \%)$ \\
\hline IVth Year & $10(20.4 \%)$ \\
\hline$V^{\text {th }}$ Year & $9(18.36 \%)$ \\
\hline Severe Stress & $33(12.1 \%)$ \\
\hline Ist year & $12(36.36 \%)$ \\
\hline II ${ }^{\text {nd }}$ Year & $7(21.21 \%)$ \\
\hline IIIrd Year & $8(24.24 \%)$ \\
\hline IVth Year & $5(15.15 \%)$ \\
\hline$V^{\text {th }}$ Year & $1(3 \%)$ \\
\hline
\end{tabular}

Year wise average stress score revealed that final first year students showed maximum stress score (22.9) and the least score was 19 among the final year students (Table 4). There was no statistical difference between the stress scores between the year of study ( $p>0.05)$. Most of the respondents $(60 \%)$ revealed that physical problems are not the reason for stress (Table 5).

\begin{tabular}{|c|c|}
\hline Academic Year & Average Stress Score \\
\hline First year & 22.9 \\
\hline Second year & 22 \\
\hline Third year & 22.7 \\
\hline Fourth year & 20.8 \\
\hline Fifth year & 19.6 \\
\hline
\end{tabular}

\begin{tabular}{|c|c|}
\hline Frequency of Physical Problems & $\begin{array}{c}\text { Frequency } \\
\text { (Percentage) }\end{array}$ \\
\hline None of the time & $164(60.1 \%)$ \\
\hline Little time & $46(23.4 \%)$ \\
\hline Some of the time & $34(12.5 \%)$ \\
\hline Most of the time & $8(2.9 \%)$ \\
\hline All of the time & $3(1.1 \%)$ \\
\hline \multicolumn{2}{|c|}{ able 5: Physical Health Problems } \\
as a Reason for Stress
\end{tabular}

We found an association between the stress groups with the motivation to study BDS course $\left(\chi^{2} 7.14, p 0.03\right)$. There was also an association with the perception of physical problems as source of stress ( $\left.\chi^{2} 15.87, p 0.001\right)$. Further, it was seen that there was no association between the stress score and year of study $\left(\chi^{2} 5.76, p\right.$ 0.22) or category of admission $\left(\chi^{2} 3.77, p\right.$ $0.15)$ or the influence of mother tongue $\left(\chi^{2} 6.2, p 0.12\right)$ or the medium of instruction at school $\left(\chi^{2} 0.78, p 0.78\right)$.

\section{DISCUSSION}

This study was primarily conducted to assess the sources of stress perceived by the dental students in all the five years of their BDS programme at Mamata Dental College, Khammam, Telangana. The different sources of stress that we included in our study were the year of study, (b) mode of admission either government or management quota, (c) motivation to join the course, (d) mother tongue, (f) language medium at school level, and (g) presence of perceived physical problems as the source of stress. The syllabus and examination scheme is as per the BDS Undergraduate Ordinance of the NTR University of Health Sciences to which all the dental teaching institutions of Andhra Pradesh are affiliated.

Our study population had more females when compared with the males, which is a usual phenomenon these days that more female students take up dental profession in India. ${ }^{9}$ There has been similar reports in the medical curriculum too that female students taking up medical career. ${ }^{10}$ Our study revealed $75 \%$ of our respondents were female and $25 \%$ were males. Our study revealed that $58 \%$ of our total population was stressed either in mild, moderate or severe category. Similar results have been observed in other studies both India and abroad.11,12 The stress in the academic professional could be multifactorial. Pre-clinical student stress could be due to the fact that they are not able to cope up the amount of subjects and assignments and the exams they have to undergo. There have been reports that the stress in the clinical students could be due to the skills that they have to acquire during these years, failing which they will be unsuccessful in their career.

Most of the studies have reported that the clinical year students are having more stress compared to the preclinical students. ${ }^{13,14}$ This could be due to the fact that the students have to excel in both the academic and clinical aspects of the dental education. But our data indicates that the average stress score of the first year students were higher compared with the final year students, even though there was no statistical difference between the groups. One reason could be of the reason that the internship students did not have any exams to appear for. In all the three different classes of stress group, the first year students had the highest stress score compared to the final year. Similar observation was also found in the average stress score among all the year of study. We could not find any reason for these observations. It may be due to the 
fact that the preclinical students were more stressed in getting adjusted to the dental curriculum compared with acquiring skills in the final year students.

Our significant observation from this study is the association of stress with physical problem as the source of stress and the association of stress with the motivation to study the course. There are studies which show the similar lines of results.15,16 Our study population included almost equal distribution of government and management quota students. It is an accepted fact that some of the students mostly among the management quota students may not be interested to take up the dental curriculum. Lack of interest could be the commonest non-academic reason for stress in these students. When the students are forced to join a dental school, which is not of their choice. There can be two reasons for this. First one is the government quota students who took up dental career might be interested in medical and were forced to take up dental because their state entrance ranking was not enough to get into medical seat and hence forced to take up dental seat. Or it can be due to the financial constraints that did not allow them to take up medical career. ${ }^{17}$ The second reason could be due to the parental pressure or family responsibility as the children cannot refuse their parents' wish, especially in a country like India. There has been a report which says that the stress was higher in dental students who joined the dental curriculum due to the parents' wish or they had a different field of choice. ${ }^{18}$

In summary, this study was conducted to assess the level of academic stress among the dental students of Mamata Dental College, Telangana. Our preliminary findings are that $58 \%$ of our total sample showed either mild or moderate or severe form of stress. These findings are in existence with other reports in dental education or medical or any other professional education. These reports has to be treated with prime importance, as it shows that half of our future student population is stressed during their professional education, which will have a long-lasting impact on their future.

\section{REFERENCES}

1. Steckler T, Kalin NH, Reul JMHM. Handbook on stress and the brain. Amsterdam, Netherlands: Elsevier Science 2005; Vol 15.

2. McEwen BS. Protective and damaging effects of stress mediators: central role of the brain. Prog Brain Res 2000;122:25-34.

3. Murphy RJ, Gray SA, Sterling G, et al. A comparative study of professional student stress. J Dent Educ 2009;73(3):328-37.
4. Ross S, Cleland J, Macleod MJ. Stress, debt and undergraduate medical student performance. Med Educ 2006;40(6):584-9.

5. Dahlin M, Joneborg N, Runeson B. Stress and depression among medical students: a cross sectional study. Med Educ 2005;39(6):594-604.

6. Zocolillo M, Murphy GE, Wetzel RD. Depression among medical students. J Affect Disord 1986;11(1):91-6.

7. Howes OD, Salkovskis PM. Health anxiety in medical students. Lancet 1998;351(9112):1332.

8. Kessler RC, Andrews G, Colpe LJ, et al. Short screening scales to monitor population prevalence and trends in non-specific psychological distress. Psychol Med 2002;32(6):959-76.

9. Tandon S. Challenges to the oral health workforce in India. J Dent Educ 2004;68(7):28-33.

10. Thomas C. Assessment of mental distress in undergraduate medical students. Journal of Educational Research and Medical Teacher 2014;2(1):14-7.

11. Ahmad MS, Md Yusoff MM, Razak AI. Stress and its relief among undergraduate dental students in Malaysia. Southeast Asian J Trop Med Public Health 2011;42(4):996-1004.

12. Bathla M, Singh M, Kulhara P, et al. Evaluation of anxiety, depression and suicidal intent in undergraduate dental students: a cross-sectional study. Contemporary Clinical Dentistry 2015;6(2):215-22.

13. Tangade PS, Mathur A, Gupta R, et al. Assessment of stress level among dental school students: an Indian outlook. Dent Res J 2011;8(2):95-101.

14. Al-Samadani $\mathrm{KH}, \mathrm{Al}$-Dharrab A. The perception of stress among clinical dental students. Word J Dent 2013;4:24-8.

15. Divaris K, Mafla AC, Villa-Torres L, et al. Psychological distress and its correlates among dental students: a survey of 17 Colombian dental schools. BMC Med Educ 2013;13:91.

16. Reddy V, Naveenm N, Prabhu, et al. The evaluation of perceived stress and depression in dental undergraduates. Int Dent J Stud Res 2013;1:36-41.

17. Elangovan S, Allareddy V, Singh F, et al. Indian dental education in the new millennium: challenges and opportunities. J Dent Educ 2010;74(9):1011-6.

18. Acharya S. Factors affecting stress among Indian dental students. J Dent Educ 2003;67(10):1140-8. 